\title{
Cigarette smoking significantly increases basal metabolic rate in patients with rheumatoid arthritis
}

\author{
G S Metsios, ${ }^{1}$ A Stavropoulos-Kalinoglou, ${ }^{1}$ A M Nevill, ${ }^{1}$ K M J Douglas, ${ }^{2}$ Y Koutedakis, ${ }^{1}$ \\ G D Kitas ${ }^{2}$
}

${ }^{1}$ School of Sport, Performing Arts and Leisure, University of Wolverhampton, Walsall, UK;

${ }^{2}$ Department of Rheumatology, Dudley Group of Hospitals NHS Trust, Russell's Hall Hospital, Dudley, UK

Correspondence to: Giorgos S Metsios, Research Institute in Healthcare Science, Department of Biomedical

Sciences, University of

Wolverhampton,

Wolverhampton, West

Midlands; gm@wlv.ac.uk

Accepted 7 May 2007

Published Online First

11 May 2007

\section{ABSTRACT}

Objective: Basal metabolic rate (BMR) is the most important indicator of human metabolism and its abnormalities have been linked to undesirable health outcomes. Cigarette smoking associates with increased BMR in healthy individuals; it is also related with worse disease outcomes in patients with rheumatoid arthritis (RA), in whom BMR is high due to hypercatabolism caused by systemic inflammation. We aimed to investigate whether smokers with RA demonstrated higher BMR levels than their non-smoking counterparts. Methods: A total of 53 patients with RA (36 female, 17 male, 20 current smokers) were assessed for: BMR (indirect calorimetry), anthropometrical data, fat-free mass (bioelectrical impedance), physical function (health assessment questionnaire; $\mathrm{HAO}$ ) and disease activity (disease activity score DAS28 and C reactive protein).

Results: RA smokers and non-smokers were not significantly different for age, height, weight, body mass index and fat-free mass. Compared to non-smokers, smokers with RA demonstrated significantly higher BMR (mean (SD) 1513.9 (263.3) vs 1718.1 (209.2) kcal/day; $p<0.001)$ and worse HAO (1.0 (0.8) vs $1.7(0.8)$; $p=0.01$ ). The BMR difference was significantly predicted by the interaction smoking/gender $(p=0.04)$. BMR was incrementally higher in light, moderate and heavy smokers $(p=0.018)$, and correlated with the daily number of cigarettes smoked $(r=0.68, p=0.04)$.

Conclusion: Current cigarette smoking further increases BMR in patients with RA and has a negative impact on patients' self-reported functional status. Education regarding smoking cessation is needed for the RA population.

Basal metabolic rate (BMR), the main indicator of human metabolism, is a vital physiological function providing for bioenergetics, body composition and by-product removal, and is largely affected by perturbations of the body's internal and/or external environment. ${ }^{1}$ Inflammatory disease, ${ }^{2}{ }^{3}$ cancer, ${ }^{4}$ human immunodeficiency virus infection, ${ }^{5}$ critical illness, ${ }^{6}$ as well as active ${ }^{7}$ and passive ${ }^{8}$ smoking are factors that significantly increase BMR and disturb normal metabolic processes.

Rheumatoid arthritis (RA), the commonest chronic inflammatory joint disease, is accompanied by a set of metabolic abnormalities collectively referred to as rheumatoid cachexia. This abnormal metabolic response is mainly due to excessive production of tumour necrosis factor alpha (TNF $\alpha$ ): this causes significant elevation in BMR and enhances protein catabolism, resulting in involuntary and rapid wasting of muscle mass. ${ }^{9}$ Rheumatoid cachexia has also been closely asso- ciated with augmented abdominal fat deposition ${ }^{10}$ increased cardiovascular risk, ${ }^{2}$ and compromised muscle strength, balance and functional ability; as such, it is a significant overall contributor to comorbidity and reduced life-expectancy in RA. ${ }^{11}$ Ideally, any factors associated with increasing metabolism in RA should be identified and, if possible, eliminated early in the course of the disease.

In healthy subjects, current cigarette smoking significantly augments resting metabolism. ${ }^{12}$ The impact of smoking on BMR has not been assessed in patients with RA. However, smoking has been implicated in the aetiology, ${ }^{13} 14$ severity ${ }^{15}$ and cardiovascular co-morbidity ${ }^{16}$ of this disease. The aim of the present study was to investigate whether RA patients who are current cigarette smokers have higher BMR levels than RA patients who have never smoked.

\section{METHODS}

\section{Participants}

A total of 53 consenting volunteers ( 36 females, 17 males; 20 current cigarette smokers, 33 nonsmokers) with RA were recruited from rheumatology outpatient clinics of the Dudley Group of Hospitals NHS Trust in the UK. All patients met the retrospective application of the revised 1987 American College of Rheumatology (ACR) classification criteria ${ }^{18}$ as well as the inclusion and exclusion criteria for this study (table 1). The presence or absence of inclusion/exclusion criteria was on the basis of patient history and was further verified by review of hospital and, where necessary, primary care notes, all their medications and relevant blood tests (eg, thyroid function tests, fasting glucose, liver function tests). The patients included in this study comprised a subgroup of a larger group of 82 RA patients recruited consecutively from these clinics for assessment of BMR, as part of another study. The present study however, included only patients who had never smoked or were current cigarette smokers: ex-smokers, and patients smoking cigars, pipes or other substances were excluded. Smokers were further divided into three subgroups according to the number of cigarettes smoked per day (light smokers: $<5$, moderate smokers: $5-9$, heavy smokers: $\geqslant 10$ ). RA patients had to be on stable medication for at least 3 months prior to assessment.

Information was given to all participants in verbal and written format, and a special follow-up visit was arranged in the rheumatology research unit for final consent and assessment. The study had prior approval by the local research ethics 
Table 1 Inclusion and exclusion criteria for the current rheumatoid arthritis (RA) patients

\begin{tabular}{ll}
\hline Inclusion criteria & Exclusion criteria \\
\hline $\begin{array}{l}\text { Patients fulfilling } 1987 \text { American } \\
\text { College of Rheumatology } \\
\text { classification criteria for RA, } \\
\text { irrespective of age, sex, disease }\end{array}$ & Hyper- or hypothyroidism \\
activity, disease duration, treatment & \\
or anthropometrical characteristics. & \\
On stable medication for $\geqslant 3$ months & Diabetes mellitus \\
prior to assessment & Malabsorption of any cause \\
& Chronic liver failure \\
& Pregnancy \\
& Current or chronic diarrhoea \\
& Proteinuria \\
& Obstructive or restrictive lung disease \\
& Congestive heart failure \\
& Current infection \\
& Ex-cigarette smokers, or current cigar, \\
& pipe or other substance smokers \\
\hline
\end{tabular}

committee and the Dudley Group of Hospitals Research and Development Directorate.

\section{Procedures}

All participants attended a single $2 \mathrm{~h}$ laboratory session after visiting the data collection site early in the morning (8:00-9:00 a.m.) following a 12-h overnight fast. Demographic and anthropometrical characteristics were recorded first, BMR was measured next, and a blood sample with assessment of the disease activity score (DAS28 ${ }^{19}$ and health assessment questionnaire (HAQ) were performed last. Standing height was measured to the nearest $0.5 \mathrm{~cm}$ (Seca Stadiometer 208, Vogel \& Halke, Hamburg, Germany). Body mass was measured to the nearest $0.1 \mathrm{~kg}$ and body composition was evaluated by bioelectrical impedance, using a segmental body composition analyser (Tanita BC 418 MA, Tanita, Tokyo, Japan). Several other methods for assessing body composition, such as dual energy $x$ ray absorptiometry, underwater weighing, total body water, and total body nitrogen may be superior for studies assessing specifically body composition, ${ }^{20}{ }^{21}$ but are cumbersome and require specialised equipment and personnel. Bioelectrical impedance, particularly based on eight electrodes as in this study, has been shown to be accurate in the general population ${ }^{22}$ as well as in patients with $\mathrm{RA},{ }^{20}$ and has the advantage of simplicity and reproducibility in the routine clinical setting. ${ }^{10}$ $\mathrm{BMR}$ was measured via indirect calorimetry, adhering to welldescribed methodological standards. ${ }^{23}$ Participants rested for a 20 -min period prior to the measurement in a semi-darkened, quiet and thermoregulated $\left(22^{\circ} \mathrm{C}\right)$ room. An automated gas analyser (Metalyzer, Cortex Biophsik, Borsdorf, Germany), calibrated before each test using standard gases of known concentration, was used to record respiratory parameters every $20 \mathrm{~s}$, while subjects inspired room air through a free-breathing face mask. Data were collected over a period of $40 \mathrm{~min}$ with the participants being instructed to refrain from sleeping or hyperventilating. Mean values of BMR for that period excluding the first and last $5 \mathrm{~min}$ were calculated using the Weir equation. ${ }^{24}$ Contemporary RA disease activity was measured using the erythrocyte sedimentation rate (ESR) and C-reactive protein (CRP), both routinely measured in the laboratories of the Dudley Group of Hospitals; and clinically using the DAS28 ${ }^{19}$ performed by a single specialist metrology nurse. Disease severity (reflected in physical dysfunction) was assessed using the HAQ. Disease duration (from symptom onset) was recorded.

\section{Statistical analyses}

Routine pre-analysis screening using the Kolmogorov-Smirnov normality tests were conducted to detect whether the studied variables were normally distributed. Comparisons between RA smokers and non-smokers for the three not normally distributed variables (ie, disease duration, CRP and ESR in table 2) were conducted using non-parametric tests (Mann-Whitney U test), and results are presented as median (range). All other (normally distributed) variables were compared using parametric statistics (Student $t$ tests) and results are presented as mean (SD). For statistically significant differences in normally distributed variables between the smoker and non-smoker RA groups, the $95 \%$ confidence intervals (95\% CI) are also reported. One-way ANOVA was adopted to examine whether mild, moderate and heavy RA smokers had different levels of BMR. Pearson's and Spearman's correlations were employed, as appropriate, to assess whether parameters previously reported to influence $\mathrm{BMR}$, ie demographic (gender, age), anthropometrical (height, weight, body mass index (BMI) and fat-free mass (FFM)) and disease related (CRP, DAS28, ESR) ${ }^{12925}$ showed associations with BMR in these RA patients. ANCOVA was used to detect if smoking was a significant factor influencing BMR after adjusting for variables that were found to significantly influence BMR. All statistical analyses were conducted using SPSS (version 13.0.1, Chicago, Illinois, USA), and statistical significance was set at $\mathrm{p}<0.05$.

\section{RESULTS}

Demographic, anthropometrical and disease-related characteristics, are shown in table 2. There were no significant differences between RA smokers and non-smokers in any of the parameters assessed apart from disease severity as assessed by the HAQ and BMR: HAQ physical disability was significantly worse (mean (SD) $1.66(0.8)$ vs $1.04(0.8) ; p=0.01,95 \% C I-1.1$ to -0.1$)$, and BMR was significantly higher (1718.1 (209.2) vs 1513.9 (263.3) kcal/day; $\mathrm{p}<0.001,95 \%$ CI -343.4 to -65.1 ) in smokers compared to non-smokers (table 2). Within RA smokers, BMR levels were significantly different between the light (1523.8 (192.3) kcal/day), moderate (1723.4 (180.7)) and heavy (1850.7 (154.6) $\mathrm{kcal} /$ day) smokers $(\mathrm{p}=0.018)$. The number of cigarettes smoked correlated significantly with BMR $(r=0.61, p=0.04)$. A similar, but non-significant $(p>0.05)$, difference was found for the HAQ between light (1.4 (0.9)) moderate $(1.6(0.9))$ and heavy $(1.9(0.8))$ smokers.

In the entire cohort of RA patients $(n=53)$, BMR showed significant correlations with age $(r=-0.36, p=0.008)$, height $(r=0.59, p<0.001)$, weight $(r=0.71, p<0.001)$, BMI $(r=0.51$, $\mathrm{p}<0.001)$ and FFM $(r=0.72, p<0.001)$. In addition, BMR significantly correlated with CRP and DAS28 $(r=0.36$, $p=0.008$ and $r=0.27, p=0.47$, respectively). ANCOVA showed that after adjustment for the factors that significantly correlated with BMR, the difference in BMR was significantly attributed to the association of smoking/gender $\left(\mathrm{F}_{1,38}=4.3\right.$, $\mathrm{p}<0.05$ ) but not either of these factors alone (smoking $\mathrm{F}_{1,38}=0.59, \mathrm{p}>0.05$; gender $\left.\mathrm{F}_{1.38}=0.14, \mathrm{p}>0.05\right)$; despite the fact that, no significant differences were observed in the factors that influence resting metabolism between female smokers and non-smokers (mean (SD) age: 57.1 (13.6) vs 62.9 (10.9) years; BMI: 25.4 (5.9) vs 25.7 (4.1) kg/m², FFM: 41.6 (6.0) vs 40.5 


\section{Extended report}

Table 2 Demographic, anthropometric and disease-related characteristics for the rheumatoid arthritis (RA) patients assessed in this study

\begin{tabular}{|c|c|c|c|c|}
\hline & RA Smokers $(n=20)$ & $\mathbf{p}$ & RA non-smokers ( $n=33$ ) & Total RA ( $n=53$ ) \\
\hline \multicolumn{5}{|l|}{ Demographic } \\
\hline \multicolumn{5}{|l|}{ Gender } \\
\hline Males & 5 & - & 12 & 17 \\
\hline Females & 15 & & 21 & 36 \\
\hline Age (years, mean (SD)) & $58.2(12.0)$ & 0.07 & $64.1(11.2)$ & $61.9(11.7)$ \\
\hline \multicolumn{5}{|l|}{ Anthropometrical } \\
\hline Height $(\mathrm{cm}$, mean (SD)) & $164.5(9.8)$ & 0.26 & $161.6(8.8)$ & $162.7(9.2)$ \\
\hline Weight $(\mathrm{kg}$, mean (SD)) & $72.5(19.7)$ & 0.32 & $67.7(15.0)$ & $69.5(16.9)$ \\
\hline Body mass index $\left(\mathrm{kg} / \mathrm{m}^{2}\right.$, mean (SD)) & $26.2(5.8)$ & 0.69 & $25.7(4.4)$ & $25.9(4.9)$ \\
\hline Fat free mass $(\mathrm{kg}$, mean $(\mathrm{SD}))$ & $45.8(10.8)$ & 0.46 & $44.6(9.4)$ & $45.1(9.8)$ \\
\hline \multicolumn{5}{|l|}{ Disease-related } \\
\hline C-reactive protein $(\mathrm{mg} / \mathrm{L})$ & $14.5(7.2-35.2)$ & 0.22 & $10.0(7.0-18.0)$ & $10.0(7.0-27.0)$ \\
\hline Disease activity score 28 (mean (SD)) & $4.6(1.5)$ & 0.14 & $4.1(1.1)$ & $4.3(1.2)$ \\
\hline Erythrocyte sedimentation rate $(\mathrm{mm} /$ first $\mathrm{h})$ & $24.5(10.5-41.7)$ & 0.58 & $20(10.5-31.0)$ & $22.0(10.5-35)$ \\
\hline Disease duration (years) & $7.5(5.2-19)$ & 0.94 & $10.0(3.0-16.0)$ & $9.0(5.0-16.0)$ \\
\hline Health assessment questionnaire (mean (SD)) & $1.7(0.8)$ & $0.0195 \% \mathrm{Cl}-1.1$ to -0.1 & $1.0(0.8)$ & $1.3(0.9)$ \\
\hline Basal metabolic rate $(\mathrm{kcal} / \mathrm{day}$, mean (SD)) & $1718.1(109.2)$ & $<0.00195 \% \mathrm{Cl}-343.4$ to -65.1 & $1513.8(263.3)$ & $1590.9(262.0)$ \\
\hline
\end{tabular}

Significant differences were only detected between BMR and HAO between smokers and non-smokers with RA.

(4.0) kg; CRP: 11.0 (6.0-38.0) vs 10.0 (6.0-14.0) mg/L, respectively, all at $\mathrm{p}>0.05), \mathrm{BMR}$ was significantly increased in the former group (female smokers: 1652.2 (202.4) vs non-smokers: $1452.1(180.7) \mathrm{kcal} /$ day, respectively, $\mathrm{p}=0.001$ and $95 \% \mathrm{CI}$ -394.1 to 120.4). A similar trend was observed in males (smokers: 1810.4 (101.6) vs non-smokers: 1690.6 (327.1) kcal/ day), however, this was not significant ( $p>0.05)$. Smoking appeared to be a more powerful predictor of BMR than either $\operatorname{CRP}\left(\mathrm{F}_{1,38}=1.0, \mathrm{p}=0.31\right)$ or DAS28 $\left(\mathrm{F}_{1,38}=0.03, \mathrm{p}=0.86\right)$.

\section{DISCUSSION}

This study shows that current cigarette smokers with RA have significantly higher BMR than patients with RA who have never smoked. As previously described in normal ${ }^{1925}$ and diseased $^{26-29}$ populations, BMR in the total group of RA patients studied here was influenced by several demographic and anthropometrical characteristics (including age and FFM), as well as inflammatory disease activity ${ }^{39}$ The groups of RA smokers and non-smokers were not significantly different for any of these characteristics, and the difference in BMR remained robust even after statistical adjustment for them, suggesting that it was predominantly, if not exclusively, due to smoking.

The expected BMR in healthy normal individuals of similar age and anthropometrical characteristics to the patients studied here would be approximately $1400 \mathrm{kcal} /$ day $^{30}{ }^{30} \mathrm{RA}$ non-smokers in this study had a mean BMR $8 \%$ higher (just over $1500 \mathrm{kcal} /$ day) while RA smokers demonstrated a mean BMR $20 \%$ higher than this (over $1718 \mathrm{kcal} /$ day). A BMR increase of more than $12 \%$ above normal levels has been reported to have detrimental health implications, particularly when the extra energy derives from muscle catabolism. ${ }^{23}$ Active $\mathrm{RA}^{9}$ or smoking ${ }^{31}$ may independently or in tandem result in loss of FFM, leading to compromised muscle strength and balance, functional disability, and immune dysfunction. ${ }^{11}$ It seems reasonable to suggest therefore, that through such a mechanism, smoking may further enhance the deleterious consequences of ongoing inflammation in RA, and this would be partly supported by the finding in the present study that RA smokers had worse physical function than non-smokers, as assessed by the HAO.

The suggestion that smoking plays an important role is further supported by the finding that smoking appears to be a stronger predictor of increased BMR than disease activity, and of a stepwise BMR increase between light, moderate and heavy smokers, together with the direct significant correlation between BMR and the number of cigarettes smoked, and the finding that the smoking/gender interaction is a significant predictor of BMR. These results reveal that it is female patients that have the most pronounced effects in BMR as a result of smoking; the same trend was observed in males but it was not statistically significant, probably due to the small number of male smoking RA patients included in this study. Overall, these findings suggest that smoking causes a dose-dependent increase in BMR, which is in line with previous reports in normal populations. ${ }^{72}$ Acute (eg, immediate increase in oxygen demand ${ }^{32}$ ) and chronic (eg, elevated thyroxin level ${ }^{33}$ ) physiological changes due to smoking may account for increases in BMR.

Smoking in RA has attracted considerable research interest for many years. Smoking is a factor that has been linked to the aetiopathogenesis of the disease, ${ }^{34-37}$ particularly in the context of concurrent genetic predisposition. ${ }^{13}{ }^{14}$ It appears to associate with greater disease activity and overall severity ${ }^{15} 3839$ as well as extra-articular manifestations including rheumatoid nodules, ${ }^{40}$ vasculitis ${ }^{17}$ and accelerated atherosclerosis. ${ }^{16}$ Smoking has also been linked to imbalances in the production of TNF $\alpha$ and soluble TNF receptors, leading to a relative excess of TNF $\alpha{ }^{41}$ This may be one of the mechanisms leading to the increased hypermetabolism specifically in RA smokers, as observed in the present study.

Although this study did not intent to identify the clinical implications of the increased BMR due to smoking, it could be argued that the significant increase in $\mathrm{HAO}$, suggests that smoking negatively affects the patients' self-reported functional status. Smoking, together with age, gender, education, exercise, BMI and number of co-morbidities, have previously been described as important determinants of $\mathrm{HAO}$ disability. ${ }^{42}$ Hypermetabolism in RA has also been linked to increased disability, reduced quality of life and premature mortality: ${ }^{21}$ it is likely that the additional smoking-induced elevation of BMR will have further negative effects (eg, increased protein catabolism) on the health status of this population. The present findings add further reasons to suggest that the RA population has to be specifically targeted for smoking cessation. ${ }^{43}$

Acknowledgements: The Department of Rheumatology, Dudley Group of Hospitals, has an infrastructure support grant from the Arthritis Research Campaign (no. 17 682). 
Funding: This study was funded by the Dudley Group of Hospitals R\&D directorate cardiovascular programme grant and a Wolverhampton University equipment grant. GSM was supported by the Greek State Scholarship's Foundation (IKY).

Competing interests: None declared

\section{REFERENCES}

1. Poehlman ET. A review: exercise and its influence on resting energy metabolism in man. Med Sci Sports Exerc 1989;21:515-25.

2. Rall LC, Roubenoff R. Rheumatoid cachexia: metabolic abnormalities, mechanisms and interventions. Rheumatology (Oxford) 2004;43:1219-23.

3. Metsios GS, Stavropoulos-Kalinoglou A, Koutedakis Y, Kitas GD. Rheumatoid cachexia: causes, significance and possible interventions. Hospital Chronicles 2006;1:20-6.

4. Staal-van den Brekel AJ, Dentener MA, Schols AM, Buurman WA, Wouters EF Increased resting energy expenditure and weight loss are related to a systemic inflammatory response in lung cancer patients. J Clin Oncol 1995:13:2600-5.

5. Batterham MJ. Investigating heterogeneity in studies of resting energy expenditure in persons with HIV/AIDS: a meta-analysis. Am J Clin Nutr 2005;81:702-13.

6. Zauner A, Schneeweiss B, Kneidinger N, Lindner G, Zauner C. Weight-adjusted resting energy expenditure is not constant in critically ill patients. Intensive Care Med 2006;32:428-34.

7. Collins LC, Walker J, Stamford BA. Smoking multiple high- versus low-nicotine cigarettes: impact on resting energy expenditure. Metabolism 1996:45:923-6.

8. Metsios GS, Flouris AD, Jamurtas AZ, Carrillo AE, Kouretas D, Germenis AE, et al. A brief exposure to moderate passive smoke increases metabolism and thyroid hormone secretion. J Clin Endocrinol Metab 2007:92:208-11.

9. Roubenoff R, Roubenoff RA, Cannon JG, Kehayias JJ, Zhuang H, Dawson-Hughes B, et al. Rheumatoid cachexia: cytokine-driven hypermetabolism accompanying reduced body cell mass in chronic inflammation. J Clin Invest 1994;93:2379-86.

10. Stavropoulos-Kalinoglou A, Metsios GS, Koutedakis Y, Nevill AM, Douglas KM, Jamurtas A, et al. Redefining overweight and obesity in rheumatoid arthritis patients. Ann Rheum Dis 2007;66:1316-21.

11. Walsmith J, Roubenoff R. Cachexia in rheumatoid arthritis. Int J Cardiol 2002;85:89-99.

12. Walker JF, Kane CJ. Effects of body mass on nicotine-induced thermogenesis and catecholamine release in male smokers. Sheng Li Xue Bao 2002;54:405-10.

13. Klareskog L, Padyukov L, Alfredsson L. Smoking as a trigger for inflammatory rheumatic diseases, Curr Opin Rheumatol 2007:19:49-54.

14. Criswell LA, Saag KG, Mikuls TR, Cerhan JR, Merlino LA, Lum RF, et al. Smoking interacts with genetic risk factors in the development of rheumatoid arthritis among older Caucasian women. Ann Rheum Dis 2006;65:1163-7.

15. Papadopoulos NG, Alamanos Y, Voulgari PV, Epagelis EK, Tsifetaki N, Drosos AA. Does cigarette smoking influence disease expression, activity and severity in early rheumatoid arthritis patients? Clin Exp Rheumatol 2005;23:861-6.

16. Gerli R, Sherer Y, Vaudo G, Schillaci G, Gilburd B, Giordano A, et al. Early atherosclerosis in rheumatoid arthritis: effects of smoking on thickness of the carotid artery intima media. Ann NY Acad Sci 2005;1051:281-90.

17. Turesson C, Schaid DJ, Weyand CM, Jacobsson LT, Goronzy JJ, Petersson IF, et al. Association of HLA-C3 and smoking with vasculitis in patients with rheumatoid arthritis. Arthritis Rheum 2006:54:2776-83.

18. Arnett FC, Edworthy SM, Bloch DA, McShane DJ, Fries JF, Cooper NS, et al. The American Rheumatism Association 1987 revised criteria for the classification of rheumatoid arthritis. Arthritis Rheum 1988:31:315-24.

19. Prevoo ML, van't Hof MA, Kuper HH, van Leeuwen MA, van de Putte LB, van Riel PL. Modified disease activity scores that include twenty-eight-joint counts. Development and validation in a prospective longitudinal study of patients with rheumatoid arthritis. Arthritis Rheum 1995;38:44-8.

20. Heitmann BL, Kondrup J, Engelhart M, Kristensen JH, Podenphant J, Hoie H, et al. Changes in fat free mass in overweight patients with rheumatoid arthritis on a weight reducing regimen. A comparison of eight different body composition methods. Int J Obes Relat Metab Disord 1994;18:812-9.

21. Demura S, Kobayashi H, Tanaka K, Sato S, Nagasawa Y, Murase T. Comprehensive evaluation of selected methods for assessing human body composition. Appl Human Sci 1999;18:43-51.
22. Demura S, Sato S, Kitabayashi T. Estimation accuracy of percent total body fat and percent segmental fat measured by single-frequency bioelectrical impedance analysis with 8 electrodes: the effect of difference in adiposity. J Sports Med Phys Fitness 2005;45:68-76.

23. Compher C, Frankenfield D, Keim N, Roth-Yousey L. Best practice methods to apply to measurement of resting metabolic rate in adults: a systematic review. J Am Diet Assoc 2006;106:881-903.

24. Weir JB. New methods for calculating metabolic rate with special reference to protein metabolism. Nutrition 1990:6:213-21.

25. Mifflin MD, St Jeor ST, Hill LA, Scott BJ, Daugherty SA, Koh YO. A new predictive equation for resting energy expenditure in healthy individuals. Am J Clin Nutr 1990:51:241-7.

26. Utaka S, Avesani CM, Draibe SA, Kamimura MA, Andreoni S, Cuppari L. Inflammation is associated with increased energy expenditure in patients with chronic kidney disease. Am J Clin Nutr 2005;82:801-5.

27. Avesani CM, Draibe SA, Kamimura MA, Colugnati FA, Cuppari L. Resting energy expenditure of chronic kidney disease patients: influence of renal function and subclinical inflammation. Am J Kidney Dis 2004;44:1008-16.

28. Niskanen L, Piirainen M, Koljonen M, Uusitupa M. Resting energy expenditure in relation to energy intake in patients with Alzheimer's disease, multi-infarct dementia and in control women. Age Ageing 1993;22:132-7.

29. Lorefalt B, Ganowiak W, Palhagen S, Toss G, Unosson M, Granerus AK. Factors of importance for weight loss in elderly patients with Parkinson's disease. Acta Neurol Scand 2004;110:180-7

30. Cunningham JJ. Body composition as a determinant of energy expenditure: a synthetic review and a proposed general prediction equation. Am J Clin Nutr 1991;54:963-9.

31. Canoy D, Wareham N, Luben R, Welch A, Bingham S, Day N, et al. Cigarette smoking and fat distribution in 21,828 British men and women: a population-based study. Obes Res 2005;13:1466-75.

32. Heitzer T, Meinertz T. Prevention of coronary heart disease: smoking. Z Kardiol 2005:94(Suppl 3):iii30-42.

33. Fisher CL, Mannino DM, Herman WH, Frumkin H. Cigarette smoking and thyroid hormone levels in males. Int J Epidemiol 1997;26:972-7.

34. Hernandez Avila M, Liang MH, Willett WC, Stampfer MJ, Colditz GA, Rosner B, et al. Reproductive factors, smoking, and the risk for rheumatoid arthritis. Epidemiology 1990;1:285-91.

35. Hazes JM, Dijkmans BA, Vandenbroucke JP, de Vries RR, Cats A. Lifestyle and the risk of rheumatoid arthritis: cigarette smoking and alcohol consumption. Ann Rheum Dis 1990;49:980-2.

36. Voigt LF, Koepsell TD, Nelson JL, Dugowson CE, Daling JR. Smoking, obesity, alcohol consumption, and the risk of rheumatoid arthritis. Epidemiology 1994;5:52532.

37. Heliovaara M, Aho K, Aromaa A, Knekt P, Reunanen A. Smoking and risk of rheumatoid arthritis. J Rheumatol 1993;20:1830-5.

38. Masdottir B, Jonsson T, Manfredsdottir V, Vikingsson A, Brekkan A, Valdimarsson $H$. Smoking, rheumatoid factor isotypes and severity of rheumatoid arthritis. Rheumatology (Oxford) 2000;39:1202-5.

39. Saag KG, Cerhan JR, Kolluri S, Ohashi K, Hunninghake GW, Schwartz DA. Cigarette smoking and rheumatoid arthritis severity. Ann Rheum Dis 1997:56:463-9.

40. Nyhall-Wahlin BM, Jacobsson LT, Petersson IF, Turesson C. Smoking is a strong risk factor for rheumatoid nodules in early rheumatoid arthritis. Ann Rheum Dis 2006;65:601-6.

41. Glossop JR, Dawes PT, Mattey DL. Association between cigarette smoking and release of tumour necrosis factor alpha and its soluble receptors by peripheral blood mononuclear cells in patients with rheumatoid arthritis. Rheumatology (Oxford) 2006;45:1223-9.

42. Sokka T, Krishnan E, Hakkinen A, Hannonen P. Functional disability in rheumatoid arthritis patients compared with a community population in Finland. Arthritis Rheum 2003;48:59-63.

43. Gorman JD. Smoking and rheumatoid arthritis: another reason to just say no. Arthritis Rheum 2006:54:10-3. 